\title{
Heroínas de la Guerra de Malvinas
}

\author{
Jazmín Maccarí1 \\ Laboratorio de Políticas Públicas hacia la Cuestión Malvinas (UNLP), Argentina \\ jazminmaccari@gmail.com
}

\begin{abstract}
María Candela Ruíz ${ }^{2}$
Laboratorio de Políticas Públicas hacia la Cuestión Malvinas (UNLP), Argentina candelaruiz@outlook.com.ar
\end{abstract}

La historia de la guerra guarda verdades, silencios, historias no narradas, protagonistas no reconocidos, sentimientos oprimidos, sensaciones impensables. Abordar este hecho bélico inspira un sentimiento muy particular, donde la necesidad de esclarecer cada detalle motiva a una búsqueda ardua de la verdad.

Las mujeres fueron un eslabón primordial durante el desarrollo de la guerra. Madres, hermanas, novias, todas apoyaron sin cesar a sus esposos, hijos o novios que fueron involucrados en un conflicto que muchos conciben como nefasto e irresponsable. Formaron parte de la Guerra de Malvinas en su mayoría enfermeras (instrumentadoras quirúrgicas), radio operadoras, maestras, isleñas civiles y mujeres profesionales. Ellas son parte de nuestra historia. Estuvieron presentes en uno de los hechos que marcaría sus vidas para siempre. Pocos y casi nadie las recuerda, sus historias fueron silenciadas como consecuencia de la insistente "desmalvinización" que los gobiernos buscaron instaurar. Cada una de ellas tiene una historia particular que merece ser contada, destacada y difundida. Ellas son las mujeres de la Guerra de Malvinas, veteranas que sufrieron las mismas secuelas que los ex combatientes y que de a poco están empezando a contar sus vidas. Ellas son parte de nuestro testimonio histórico, merecen ser escuchadas y reconocidas. Ellas son "Las Heroínas Anónimas".
Este trabajo se centra en las mujeres de la Fuerza Aérea, quienes prestaron su testimonio personal. Entre ellas: Alicia Mabel Reynoso, Stella Maris Morales y Sonia Escudero. Tienen historias con diferencias específicas, pero todas con un único fin y objetivo: el reconocimiento.

- Alicia Mabel Reynoso, nació en la provincia de Santa Fe. Tomó la decisión desde pequeña de estudiar enfermería en su ciudad, con todos los desafíos que ello implicaba para la época. Finalizados sus estudios, se dirigió a Buenos Aires a ejercer su profesión, y logró desempeñar su labor en varios sanatorios. Su padre, Coronel, le había inculcado desde muy pequeña el amor por la Patria, el valor de la bandera argentina y el la relevancia de la Fuerza Armada.Con la fortaleza que la caracteriza, se dirigió y logró ser aceptada en la convocatoria.

- Stella Maris Morales, nació en un pueblo humilde de la provincia de Córdoba. Decidió dedicarse a la enfermería y trabajar de ello. Al desempeñarse en varios sanatorios se enteró lo atinente a la incorporación de enfermeras a la Guerra de Malvinas. Ingresó a la Fuerza Aérea, siendo su destino el Hospital Aeronáutico Central en Buenos Aires. Al año siguiente fue convocada para participar de la Guerra de Malvinas y dirigirse a Comodoro Rivadavia. Stella Maris manifiesta haber sentido gran emoción y orgullo ante tal convocatoria. La motivación de alistarse

1 Investigadora del Laboratorio de Políticas Públicas hacia la Cuestión Malvinas (UNLP). Integrante de la ReFem 2065. jazminmaccari@gmail.com

2 Investigadora del Laboratorio de Políticas Públicas hacia la Cuestión Malvinas (UNLP). Integrante de la ReFem 2065. candelaruiz@outlook.com.ar 
fue de índole económica, necesitaba dinero para llevar adelante su vida y ayudar a su familia, por lo que vio en la convocatoria una oportunidad para ello. Pero esto, poco a poco, fue quedando en segundo plano y la solidaridad y el amor por los seres humanos prevaleció.

- Sonia Escudero, también nació en la provincia de Córdoba. Se dedicó a la enfermería, al igual que sus compañeras. Ella, con su espíritu libre, respondió a la convocatoria motivada por la aventura. Su deseo de experimentar nuevos órdenes y ser parte de la estructura militar la llevó a alistarse en la Fuerza Aérea.

\section{Las enfermeras durante la Guerra de Malvinas}

Las instrumentadoras quirúrgicas dejaron una realidad para inmiscuirse en otra muy diferente: abandonaron sus delantales blancos y tuvieron que usar uniformes y borceguíes; y tras una breve instrucción, partieron.

Su principal misión fue atender a cientos de soldados, darle fuerzas, contención, esperanzas, y cuidarlos. Al comienzo recibían heridos que ya habían sido atendidos en los primeros auxilios en las islas, recorrían las trincheras lavando y vendando heridas. Pero esta situación fue revertida a partir de la noche del 10 de junio, cuando los ingleses redoblaron los bombardeos porque ya planificaban la ofensiva final, donde no daban abasto, y la gente que llegaba no había tenido ninguna curación previa. Estaban llenos de barro, de pólvora, de turba de Malvinas que se pegaban a las heridas.

En un principio no tenían contacto con los pacientes: ellos entraban dormidos y se iban dormidos. Pero en la ofensiva final inglesa fue distinto, estas jóvenes se transformaron en consejeras y confidentes de las penas de esos hombres que necesitaban desahogo y contención. A veces les pedían que les escribieran las cartas para sus familiares aunque muchos no tenían las manos heridas. Las enfermeras que estuvieron en la guerra durante estos diez días no durmieron y tuvieron graves problemas y secuelas de salud. En palabras de Alicia Mabel Reynoso: "Aún nos quedan muchas historias por contar, pero es todo un avance que hoy podamos romper el silencio y recuperar así la otra historia que nunca fue contada, la de las veteranas de guerra".

Ayudaban a los ex combatientes no sólo en la medicina sino también en la contención emocional. Los soldados entraban pidiendo a sus madres, hermanas, novias y les pedían que por favor se comunicaran con ellas para decirles que las querían y que estaban bien. Se sentían solos, y al verlas, sus rostros cambiaban. Ellas les inspiraban confianza, alegría, contención. Necesitaban de las mujeres para sentirse acompañados y seguros, establecieron un trato que con sus compañeros masculinos no lograban. Las enfermeras actuaron como tales pero destacamos su rol más allá de la cura de las heridas. Hicieron todo lo que estuvo a su alcance para tranquilizarlos, desde el detalle más mínimo al más grande, todo tenía por fin decirles que no se encontraban solos, que ellas estaban para lo que necesitaran. Además de ser profesionales, son mujeres y llevan consigo, internamente, su instinto maternal. Ver a los soldados en el estado en que ingresaban a las salas de emergencia era desgarrador para ellas, pero tenían que sacar fuerzas y mantenerse enteras para ellos, no demostrar tristeza era lo fundamental, necesitaban estar firmes y seguras para que los heridos tomaran fuerzas para curarse con mayor rapidez. Más que nunca demostraron su entereza como enfermeras y como mujeres. Los horrores de la guerra los vivieron en carne propia, el dolor de los soldados era su dolor, sanarlos era su tarea, contenerlos era inherente al instinto humano. Y así lo hicieron, con cada uno ellos, valiéndose de las herramientas que podían, aplicando lo aprendido, pero nada alcanzaba, aprendieron del día a día del conflicto bélico.

\section{Secuelas de la guerra}

Todas vivieron los horrores de la guerra desde adentro. Cada mujer, de una $\mathrm{u}$ otra manera, proyectó lo sucedido en la guerra a su propia vida, pues es imposible dejar los recuerdos a un lado y continuar como si nada hubiera ocurrido. Todas ellas tuvieron una etapa de recuperación después del horror. Las secuelas fueron 
psicológicos en su mayoría.. Muchas tardaron años en hablar y contar lo que vivieron en esa época, otras tuvieron problemas de salud graves y algunas quisieron olvidar para siempre lo que habían presenciado. Imposible fue dejar de lado todo lo que vivieron.

Superarlo fue una etapa de transición que todas atravesaron. Despojarse de los errores no es posible sólo por una decisión personal; en especial, cuando el gobierno de ese momento y los que le siguieron no hicieron nada para ayudarlas, ni a ellas ni a los ex combatientes. Los dejaron solos, los abandonaron creyendo que con una pensión iban a poder tapar los errores políticos cometidos durante la Guerra de Malvinas. Quisieron callarlas, re direccionarlas en distintos sectores del poder para que no hablasen de lo sucedido en aquel momento. Pero la necesidad de verdad prevaleció. Con fortaleza, Alicia Reynoso, enfermera de mayor antigüedad en la Fuerza Aérea, comenzó a dar a conocer su historia, a recordar lo que muchos olvidaron y a mantener viva la historia de Malvinas.

Contar sus historias es una forma de sanar, tal vez la única, después de tanto olvido político y social. Las lágrimas en sus ojos se dejan notar cuando hablan de lo sucedido sin vergüenza y con fortaleza, continúan contando su historia. Lágrimas de emoción, tristeza y bronca se dejan ver. A algunas les cuesta más que a otras hablar, pero todas se contienen entre sí para seguir. Ellas saben que el día en que puedan hablar sin derramar lágrimas se sentirá completamente sanas y recuperadas. Siguieron con sus vidas a pesar de lo vivido. Lograron formar sus familias, desempeñar su profesión y seguir alistadas a la Fuerza Aérea. Continuaron como pudieron y continúan con el respaldo de sus compañeras y familia. Ellas sienten un afecto profundo por la fuerza a la cual pertenecen y siguen desempeñando labores sobre la misma con orgullo.

\section{Reconocimiento}

A su regreso de la Guerra, los años que siguieron fueron de "desmalvinización": el abandono que tuvieron por parte del Estado, siendo el dolor más grande.
El reconocimiento social y revalorización a la figura del veterano y del héroe de Malvinas comenzó sobre el final del gobierno de Alfonsín, pero las mujeres quedaron afuera de la misma, sufriendo no solo el olvido de las instituciones militares sino también de la sociedad. Tuvieron que pasar 31 años para que desde el Estado se reconocieran los esfuerzos realizados por estas mujeres. Tuvieron un reconocimiento por parte de Naciones Unidas al participar junto a los Cascos Azules Argentinos en misiones humanitarias fuera del país. Obtuvieron también un reconocimiento de la Fuerza Aérea, pero les falta algo fundamental: el reconocimiento político y social que se merecen. Se debe dar a conocer su historia y hacer saber a la población que hubo mujeres en la Guerra de Malvinas, que desarrollaron un rol primordial y ejemplar y que vivieron el mismo horror que todos los que formaron parte de un conflicto bélico. Ellas no buscan una gratitud económica, tampoco ser figuras políticas. Necesitan un reconocimiento humano. Recién después de 34 años del aniversario de la Guerra de Malvinas fueron invitadas al desfile cívico-militar realizado el día 9 de Julio del corriente año. La emoción de lo que ello significó se evidenció en las lágrimas de emoción al momento de arribara las calles desfilando. El calor de la gente les hace sentir que las Malvinas están vivas y son argentinas. No escuchaban más que expresiones tales como "héroes", "levanten el estandarte bien alto", "que todos sepan que hubo mujeres en Malvinas", "gracias por todo", aplausos, ovaciones, las hicieron sentir acompañadas, las personas hicieron lo que políticamente los gobiernos durante años no hicieron, no les importó.

\section{Solo buscan un reconocimiento humano.}

Transpasaron lo vivido a lo que venía después. Esto se debió, por un lado, a que cuando terminó la guerra siguieron trabajando, les dijeron que no podían hablar de lo vivido. Eran personal militar y debían acatar la orden. Pero, por otro lado, ellas mismas se hicieron un caparazón, El cual les hizo gran daño a muchas.

Contar sus historias es una forma de sanar, tal vez la única después de la falta de 
reconocimiento y del olvido político. Alicia Reynoso, la enfermera de mayor antigüedad en la Fuerza Aérea, comenzó a contar su historia; a algunas les cuesta mucho más pero entre sí se contienen para poder continuar. Es un daño que no se va a reparar nunca pero que puede sanar al contarlo. De a poco se están animando hablar, en gran parte por el daño que ha causado el haberlas tratado como si no existieran. "Cuando tenés nombre y trabajás entre los pares y no te reconocen, es muy triste" (La Nación, 1/4/2017). Advierten la falta de reconocimiento en el intento de callarlas y en la negación de su existencia, y en caso de que no las nieguen ven muy poco apoyo de parte de sus superiores. Pero ello se suma a la decisión meramente política de excluirlas del concepto de "protagonistas" para relegarlas a un papel de no existir directamente porque, según ellas, la historia se contó por la mitad, una mitad de la que no formaban parte ni se daban atisbos de que estuvieron presentes.

"Estamos cansadas de que se cuente la media verdad de la historia. Cuando se sepa la historia completa vamos a poder elaborar el dolor. La media verdad que contaron siempre fue que no existíamos, que no habíamos estado. Estamos reconocidas por el Congreso con medalla y por la Fuerza Aérea como veteranas. Pero no cobramos la pensión por una actitud totalmente política. En los 90, en la presidencia de Carlos Menem, se firmó un decreto que dejaba afuera de los resarcimientos económicos a las personas que no habían estado en las islas, y la Fuerza Aérea tenía las bases desde donde despegaban los aviones en el continente" (Testimonio personal de Alicia Mabel Reynoso). Las mujeres de la Fuerza Aérea no están atrás de un resarcimiento económico. Aquí hay una cuestión de honor, olvido y violencia. El olvido es violencia. Casi nos borran de la historia".

\section{Opiniones y testimonios personales sobre la Guerra de Malvinas}

Las opiniones son encontradas y en algunos aspectos difieren, pero coinciden en un hecho primordial, que las Malvinas son argentinas, no hay duda de ello. No todas comparten la forma en la que se llevó a cabo, es decir, hay quienes creen que el objetivo es certero y que ir a la guerra era la única manera de resolver este conflicto pero distan en la forma en que la misma se realizó, reconociendo los errores políticos cometidos en todo lo que una guerra requiere. Por el otro lado, encontramos a quienes rechazan fehacientemente la guerra como medio para resolver un conflicto internacional. Consideran que se puede resolver en una mesa de negociaciones, sin necesidad de recurrir a un acto tan violento y horroroso como lo es la guerra. "Esta no es la solución porque lo único que deja son víctimas, tanto de quienes ganan como de quienes pierden. Bajas materiales y humanas tienen ambos bandos, al igual que un daño social. Distan en el nivel y grado de pérdidas que se obtienen, el lado victorioso menor que el derrotado, pero su victoria se hizo en base a muertes de inocentes. Héroes son los que lucharon en el campo de batalla y pusieron su cuerpo a prueba de todo, no los gobiernos que anotaron una victoria más frente al mundo. Las Malvinas son y serán siempre argentinas, en ellas descansan miles de seres humanos. A fin de cuenta, todos salen dañados, otros más, otros menos, pero una muerte basta para saber que un conflicto bélico no vale la pena por algún interés particular".

\section{Apreciación}

Como consecuencia de las malas decisiones del régimen militar, muchos grupos fueron invisibilizados, callados para no contar la verdad. Por el proceso de desmalvinización, fueron relegados diversos actores de la historia argentina, olvidados, abandonados. No recibieron el apoyo psicológico que necesitaban, ni ningún tipo de apoyo, fueron dejados a la deriva. Uno de los actores invisibilizados es el conformado por las enfermeras, que asistieron a los heridos durante la guerra. Siempre negadas a mantener una relación personal con los heridos, eran ordenadas a cumplir su deber y nada más. Durante, y sobre todo después de la guerra, sufrieron un maltrato político. Podemos considerar que fueron relegadas de la historia y de la vida de los argentinos, pocos conocen sobre su existencia y labor durante de la guerra y muchos se asombran al escuchar parte de su historia. 
Al finalizar la guerra y enterarse de la rendición fueron destinadas a otras zonas que requerían su labor. Fueron negadas a volver a sus hogares, y solo pudieron hacerlo muchos meses después de la guerra. El grado de ocultamiento al que estuvieron sometidas se evidencia en la falta de datos sobre ellas, muchas no fueron identificadas, otras continúan con secuelas que les impide hablar y dar a conocer sus historias. Solo algunas, después de muchos años, lograron contar lo que habían vivido. La guerra marcó sus vidas, las transformó y fue un punto de inflexión en ellas.

El eje de estudio se plantea a partir de observar que estas mujeres, heroínas de Malvinas, no han sido reconocidas ni están en los libros que hablan de la guerra. Realmente, si tenemos en cuenta el machismo de la sociedad argentina podremos entender que la mujer ha sido, y es, relegada de ciertos ámbitos. En lo referente a las Fuerzas Armadas, solamente incorporaba hombres, pero al llegar el enfrentamiento bélico de 1982 se hace necesaria la participación de mujeres con conocimiento en medicina. Aun así, vemos que no fueron tenidas en cuenta, pese a ser ellas quienes cuidaban, curaban y brindaban su sonrisa para que los soldados se sintieran aliviados.

Es necesario esclarecer sus historias. Finalizar con el ocultismo político que sufrieron desde 1982, por respeto y dignidad, debemos darle la relevancia que se merecen, que se hable de ellas y sean reconocidas. Existen muy pocos escritos y documentos al respecto de sus historias, y aquellos disponibles solo son partes que muchas veces pecan de confusión. Ellas día a día combaten con las secuelas, y luchan por ganarse un espacio en la conciencia nacional, espacio que se merecen. Si ellas, pese a todo lo que sufrieron, tienen fuerza para seguir y lograrlo, nosotros debemos ser su canal de difusión. 


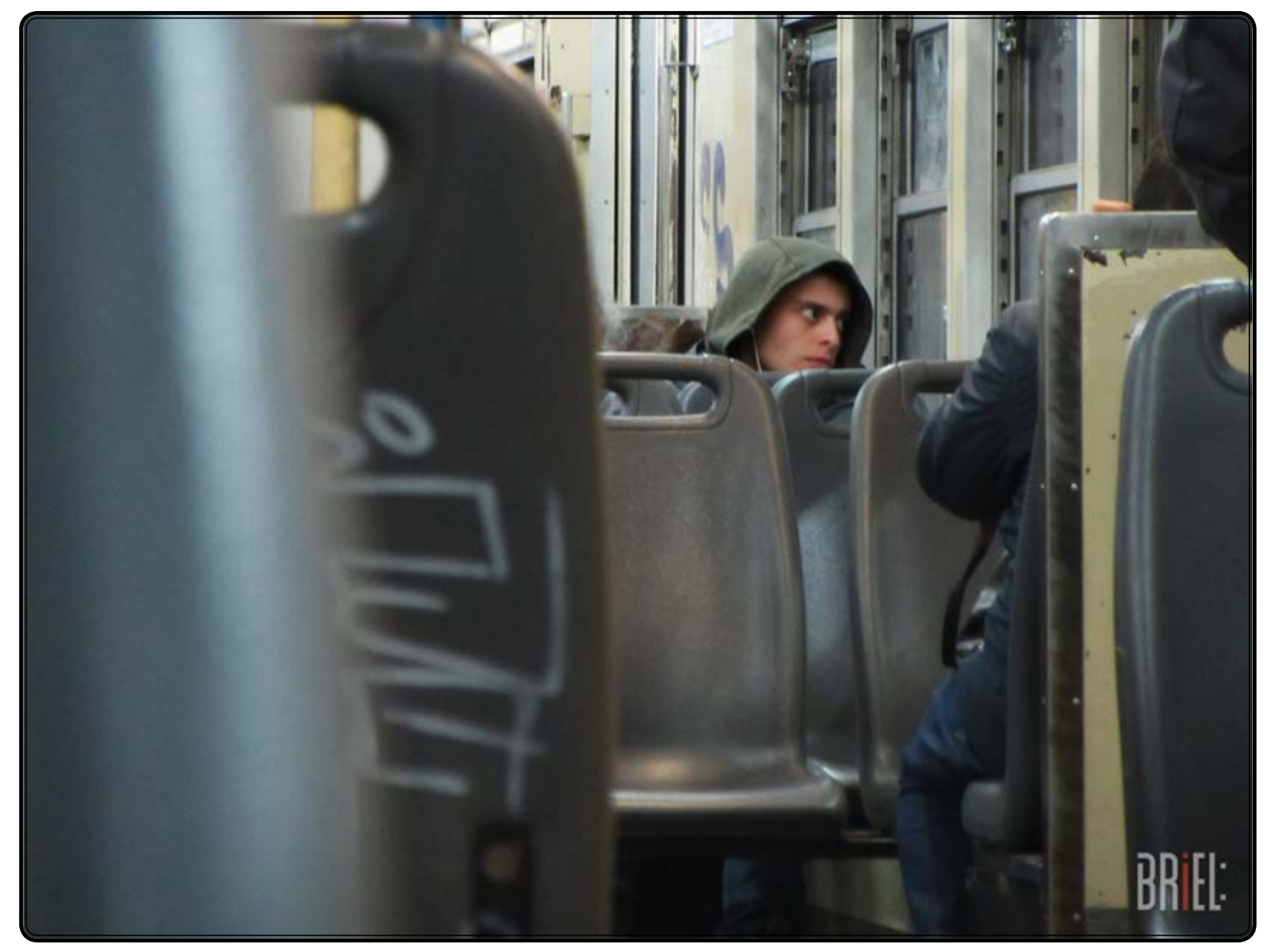

Conurmundos. 